\title{
Retrieve Logic Flow in Discourse Analysis of Academic Paper: A Case Study of Law, Law, What Is Law
}

\author{
YANG Zhuo \\ East China University of Political Science and Law, Shanghai, China
}

\begin{abstract}
The present study shall be mainly concerned with logic flow and its expressions in academic paper. It examines Law, Law, What Law? and intends to focus on two research goals: (1) to identify logic flow among clause complexes; (2) to figure out meanings and intentions of those logic expressions. The description and analysis shall demonstrate how the logic flow is achieved on two aspects of textual cohesive devices: grammatical cohesion and lexical cohesion. Any reader or translator ignores such devices of cohesion may not only get lost in the maze of language but miss subtle touches of irony, hence misreading the author's points of view.
\end{abstract}

Keywords: discourse analysis, systemic functional grammar, logic flow, descriptive translation studies

\section{Introduction}

A literal way of reading or translating often leads to misunderstanding and it is more true in case of academic papers, considering their intricate structure of logic flow. For instance, when the accuracy of "personal assessment" is questioned, the reader/translator needs to recall and locate what kind of assessment has already been mentioned in the preceding paragraph. In another case, "the same" could be a term that challenges reader/translator's short-term memory and comprehension as the entity it refers to may occur in an earlier sentence "over fairly long stretches of text” (Thompson, 2008, p. 184), ahead of the immediately preceding one. Those expressions of reference, carrying meaning puzzles, compose part of inherent logic of an academic paper.

The present study examines Law, Law, What Law? and intends to focus on two research goals: (1) to identify logic flow among clause complexes; (2) to figure out meanings and intentions of those logic expressions. The study thus has a rather tightly defined scope — cohesive devices to realize logic flow in a certain academic paper - an area in which there has been not much empirical research to date (for qualitative analysis on various instances, see Halliday and Matthiessen, 2008). It seeks to gather more descriptive information and evidence about grammatical and lexical cohesion in order to complement the findings of more macroscopic and holistic studies.

\section{Data and Method}

To gain some idea of how the logic flow takes place in academic paper, take a look at a short extract from an article titled Law, Law, What Law? written by William P. Alford. It was published in the book The Limits of the

YANG Zhuo, Ph.D., Lecturer, East China University of Political Science and Law. 
Rule of Law in China edited by Karen G. Turner, James V. Feinerman, and R. Kent Guy in Asian law series in University of Washington Press in 2000. Its official translation version to Chinese (YANG, 2017) is to be published by Law Press of China shortly. The text is chosen because the cohesive signals are unusually dense and explicit in some ways but not in others. The sentences are numbered for ease of reference.

[1]The first substantive question posed to me as I commenced my graduate work in Chinese studies during the autumn of1972 was by the late Arthur Wright, who asked why I, a young man of seeming intelligence, was intent on wasting my time on the study of Chinese legal history. [2]While reasonable people may differ about the accuracy of the kindly Professor Wright's personal assessment, there is no mistaking his query. [3]The question posed was a revealing one, mirroring a view, long prevalent in American scholarship, about the relative unimportance of law in Chinese civilization.

[4]Chinese history and society have portrayed that civilization both within academic circles and to the broader community. [5]Neither classic depictions of Chinese life, be they focused on imperial or contemporary days, nor efforts to repudiate or otherwise move beyond such studies have accorded law more than a marginal place in the Chinese landscape, if that. [6]For example, one is hard pressed to identify major Western studies of China written before the mid 1980s and not specifically focused on law that recognize imperial China's voluminous and elaborate legal codification as the impressive intellectual accomplishment that it most assuredly was. [7]Some such studies even evidence a lack of awareness of the existence of that body of positive law. [8]And few pieces of the same vintage concerning either the People's Republic of China or the Republic of China pay any heed to the impact on Chinese life of the substantial, if far from wholly successful, efforts of these more recent governments to marshal law in the attainment of their objectives. [9]Instead, law is typically treated as an afterthought, if at all, with little, if any, effort to integrate observations about it into the more general picture being offered of Chinese intellectual, social, political or economic life.

Probably the most striking feature of the text is its length of most sentences. This comes out especially in academic writing as a feature of argumentative text type. Besides, it's easy to detect on the first look that most sentence-initials are cohesive signals such as "while”, "neither”, "for example”, "some such studies”, "and”, and "instead”, pointing at information already provided.

To understand better its logic flow, the tool of cohesive devices raised by Halliday and Hasan under the framework of Systemic Functional Grammar might be of great use. They suggest that cohesion is a semantic concept and it conveys relations of meaning that exist within the text (Halliday \& Hasan, 1976). According to them, cohesion and coherence are labels used to compose "texture", which is "the quality of being recognizably a text rather than a collection of unconnected words or clauses” (Thompson, 2008, p. 179; as cited in Halliday \& Hason, 1976). To put it into details, "Cohesion refers to the linguistic devices by which the speaker can signal the experiential and interpersonal coherence of the text—and is thus a textual phenomenon[...]." and "[c]oherence, on the other hand, is [...] a mental phenomenon and cannot be identified or quantified in the same way as cohesion” (Thompson, 2008, p. 179). According to Beaugrande and Dressler (1981), a discourse should bear several qualities including cohesion and coherence to achieve its communicability. It is the cohesion devices that connect those sections into a whole. Among various devices of cohesion, there are reference, substitution, ellipsis, conjunction (all of them fall into the category of grammatical cohesion) and lexical cohesion.

In the following sections, text analysis will be based on language phenomena of substitution plus ellipsis (which is also called "zero substitution") on one aspect and lexical reference with cohesive nouns on another since they are main features of the data. The cohesive device of conjunction, important though it is in term of realizing internal logic of the English text (Martin, 2010), will not be covered due to its limited manifestation in the data. 


\section{Analysis and Findings}

\section{Substitution}

Substitution is a way of creating cohesion using a word/phrase to replace a word/phrase used earlier. For instance, "the one(s)" and "the same” can be used to replace nouns (e.g. "I'll have the same.”). Verbs can be replaced by "do" (e.g. "The authorities said they had acted, but nobody believed they had done.”). In speaking, whole clauses can be replaced by "so” or "not” (e.g. “I hope so/not.”). Halliday and Hasan (1976) believe substitution is to replace a certain word, which is just a form, and its meaning should be traced back to the context. The following analysis starts from an assumption that any clause can be interpreted in as being in a coherent relation with the clause or clauses preceding it.

In the data, it can be found that "[T]he question" in [3] echoes the "question" in [1], a strategy of simple repetition evidently. "[H] is query" in [2] points at the "question" in [1] as well. The term "his" is a possessive pronoun referring back at Arthur Wright's action of "ask[ing]" "why”. Here "query" is a synonymous substitution of the term "question", as it repeats the element in the preceding sentence ("question") in a different way, the use of which has a function of emphasizing effect and vividness of the expression.

Another case, meanwhile, takes more efforts on the reader's side to identify the language phenomenon of substitution, which is not about replacement of noun phrases any more. What does "personal assessment" in [2] refer to? The knowledge gap needs to be made up with information from the preceding sentence, in which "I", the author, receives a praise from Professor Wright for being "a young man of seeming intelligence". So the phrase "personal” can be understood as “...on the author/me” while "assessment” equals Prof. Wright's comments on the author for his "intelligence".

The third example occurs in the second paragraph. In [6] "major western studies of China written before the mid-1980s" is raised for the first time. Here the post-modifier "of China written before the mid-1980s" is technically known as "homophora” (a particular kind of exophoric reference). In [7], "some such studies” refers back to the whole stretch of the text ("major western studies of China written before the mid-1980s") mentioned above. Clause [8] starts with "few pieces of the same vintage", in which the phrase of "the same", a comparative reference, indicates substitution. Considering "the western studies" are mostly written in mid-1980s, nearly 20 years before the publishing date (as Law, Law, What is Law comes out in 2000) and they have been widely accepted and admired, it can be logically conducted by a meticulous reader that "the vintage" used here is a different name for those "major western studies" in [6], as they are also something old and respectable.

\section{Ellipsis}

Ellipsis is when we omit words because they are understood from the context. It is closely related with the concept of substitution and is even regarded as "zero-substitution" (Halliday \& Hason, 1976).

In the data, ellipsis is mainly represented by expressions such as "if that" in [5], "if any", and "if at all" in [9]. Ellipsis is a commonly used device for cohesion to avoid repetition. In an English sentence the part that has mentioned before is usually omitted. Take "if that" for example. To construct coherence, the reader needs to see "that" represents what the previous sentence clause has mentioned in the clause complex "Neither... or ... Nor ... have accorded law more than a marginal place in the Chinese landscape”. With such a flashback, it can be 
inferred that "if that" can be put as "if law has any place at all" in its full expression. Functionally speaking, "if that" serves as the extension and "distractive” (Thompson, 2008, p. 190) in its logic-semantical relations.

It's quite similar with "if at all" and "if any" in [9]. The first "if" clause refers back to the sentence clause "law is typically treated as an afterthought", so here it can be understood as "if the law is ever be treated as an afterthought at all", conveying a touch of irony in a negative tone. As for the latter "if", it is inserted in the middle of the clause "with little, if any, effort". The original information can be put as "there's little effect, if there's any effect at all”, expressing negation in a literally subtle yet strong way. It displays how the author ties to mock limited concern on law history study of China so far among Western scholars. The ellipsis reinforces the conversational tone.

In fact, what the three "if"s convey is more typical of informal speech than of formal writing, and they signal roughly the author's criticism towards the relative ignorance of Chinese law study among renowned Western scholars. Yet the cohesive devices of ellipsis function to tone down such a judgment and hence create objectiveness required of an academic paper at face value.

\section{Lexical Cohesion}

Lexical cohesion is a way of creating cohesion using synonyms (e.g. "beautiful” for "lovely") hyponyms and superordinates (e.g. "daffodil”, "rose” and "daisy”, are all hyponyms of the superordinate "flower”). In a text, lexical chains are created by using words in the same lexical set (e.g. “army”, “soldiers”, "barracks”, "weapons”). These techniques allow for the central themes to be reiterated in a way that avoids monotony for the reader.

In [4], the author uses the verb "portray" to describe actions "leading Western scholars of Chinese history and Society" take to produce favorable yet not necessarily reliable writing works on China. Literally the word means "to paint". In this context, "portray" means writing fictionally, i.e., describing reality with large dose of personal imagination. It is used as a "grammatical metaphor" which is "the expression of a meaning through a lexico-grammatical form that originally evolved to express a different kind of meaning” (Thompson, 2008, p. 223). With the linguistic token of "portray", the author expresses his personal unfavorable attitude towards western scholars' current achievements on Chinese studies, which is quite subtle to detect when viewed individually.

Nevertheless, to reinforce such an impress on the readers, the author repeats the metaphor of "portray[ing]" by comparing the study of "Chinese history and Society" among "leading western scholars" in [4] as a "depiction of Chinese life" in [5]. Also in [5], "Chinese landscape” is mentioned as anonymous substitution of the word "painting" (which does not emerge in the paragraph but is implied everywhere). To make it more reachable for knowledgeable readers, the author uses another metaphor which accords the position of Chinese law history studies to "a marginal place", as if the readers are in front of a large painting picture of Chinese life, yet failing to spot any trace of legal life description. Moreover, in [6], when "one”, i.e., the author, is pressured to "identify", not to "focus" on certain areas of study, the two process verbs are used to create a scene of a viewer observing a painting, the same as before. The metaphor of "drawing pictures" goes on. In [8], "vintage”, a term often used to address valuable ancient painting, is used to replace "major western studies" in [6] (c.f. section 1 "Substitution"), resonating the image of painting again. Eventually, in [9], it is made clear, repeatedly, that there is a "general picture" about "Chinese intellectual, social political or economic life” where law barely has any place at all. 
Now if we link all those expression of "portray" (in [4]), "depiction of Chinese life" (in [5]), "Chinese landscape” (in [5]), "vintage” (in [8])and "general picture” (in [9]) together, they correspond with each other as collocation and have formed a unbreakable lexical chain, enhancing coherence of the text with its logic.

\section{Conclusion}

To summarize, the study focuses on decoding logic matrix in a piece of academic paper with law background. It describes how the logic flow was constructed between lines and conducts discourse analysis with tools of cohesive devices under the guidance of Systemic Functional Grammar. To answer the first research question, we can say that the paper's inherent logic is achieved with both grammatical and lexical cohesion.To be specific, the former is largely realized by cohesive devices of substitution and ellipsis, the latter with a lexical chain. This study also provides instances covering shift of Theme and Rheme in the pattern of "question-query-question" throughout [1] to [3], various expressions of "Western studies", "such studies" and "the same [studies]" throughout [6][7][8], full information versions of three shortened "if" clauses, as well as a lexical chain clustered around the image of "painting" in the second paragraph through [4] to [9]. Hence, the second research question has also been dealt with.

Devices of logic flow reflect negotiation and cooperation with readers. Law, Law, What is Law serves as a great example for us to see that in some (though not all, luckily) academic papers each chunk of information would not be presented as self-contained. Io order to retrieve the logic, the readers have to value different expressions of cohesion greatly. So far, the overall effect of the text might appear difficult as the writer leaves the reader to do much coherence-construction on their own. The understanding of the text both relates outwards to the reader's knowledge of the world and relates back to meanings brought implicitly into the text. Yet the readers are treated as knowing what is being talked about while in fact they MIGHT not. Consequently, upon drawing this conclusion, it it worthwhile to "consider what cultural knowledge the reader needs in order to reconstruct the coherence” (Thompson, 2008, p. 179).

The question of translating logic also needs our attention, if it is not pushing the conclusion a little too far from such a small base. A comprehensive research into coherent reconstructing by functional stylistics will enable translators to see clearly the need to reconstruct coherence and familiarize them with various grammatical cohesive devices and cohesive function in constructing a unified coherent text. Regarding the coherence of the translated version, the omitted part must be filled, the implicit part have to be made explicit, or otherwise the meaning of the sentence or article might be changed. When it comes to translation into Chinese, in order to facilitate fluency of the text, substituting and ellipsis in the ST are encouraged to be made up with full yet concise renditions, sometime even with explanation as to downgrade difficulty in the information and regain original logic flow of English, since it is comparatively weak in Chinese language. In this regard, we are glad to see its Chinese version has attained such a goal.

\section{References}

Alford, W. P. (2000). Law law, what is law. In K. G. Turner, J. V. Feinerman and R. K.Guy (Eds.), The limits of the rule of law in China. Seattle: University of Washington Press.

Beaugrande, R., \& Dressler, W. (1981). Introduction to text linguistics. London and New York: Longman.

Halliday, M. A. K., \& Hasan, R. (1976). Cohesion in English. London: Longman UK Group Limited. 
Halliday, M. A. K., \& Mattiessen, C. (2008). An introduction to functional grammar (3rd ed.). Beijing: Foreign Language Teaching and Research Press.

Martin, J. R. (2010). Discourse semantics. Z. H. Wang, (Ed.). Shanghai: Shanghai Jiao Tong University Press.

Thompson, G. (2008). Introducing functional grammar. Beijing: Foreign Language Teaching and Research Press.

YANG, Z. (Trans.). (2017). Selection of legal history studies papers on China. Beijing: Law Press of China. 